\title{
Retraction Note: Graft fixation alternatives in anterior cruciate ligament reconstruction
}

\author{
Bernardino Saccomanni
}

Published online: 28 July 2012

(C) Istituti Ortopedici Rizzoli 2012

Retraction to: Musculoskelet Surg (2011) 95:183-191

DOI 10.1007/s12306-011-0137-4

This article has been retracted due to plagiarism.

The online version of the original article can be found under doi:10.1007/s12306-011-0137-4.

B. Saccomanni $(\bowtie)$

Orthopaedic and Traumatologic Surgery, ASL BARI,

viale Regina Margherita, 74, Altamura, Bari, Italy

e-mail: bernasacco@yahoo.it 